\title{
Entrevista a Rania Benzina. La dicotomía del proceso emancipatorio político y social de las tunecinas ${ }^{1}$
}

\section{Interview with Rania Benzina. The dichotomy of the political and social emancipatory process of Tunisian women}

\author{
Indira Sánchez Bernal \\ Departamento de Ciencia Política y Relaciones Internacionales, \\ Tecnológico de Monterrey, \\ Campus Ciudad de México (México) \\ iisanchez@tec.mx
}

\begin{abstract}
Resumen
La lucha de las mujeres tunecinas desde la década de 1980 se encuentra dividida entre el feminismo islámico y el feminismo laico. El feminismo laico critica que la emancipación política y social de las mujeres esté sustentada en la religión, porque la religión subsume el papel de la mujer en la sociedad; mientras que el feminismo islámico sostiene que la lucha contra el patriarcado se enmarca en el Islam, porque la religión ha brindado los elementos para que las mujeres sean sujetas de derecho y sujetas políticas. Desde las protestas del año 2011, la dicotomía de ambas vertientes es más profunda, especialmente tras la llegada al poder del partido Al Nahda, y se ha logrado que la reconstrucción identitaria de la mujer tunecina sea un debate entre las mujeres. La mujer tunecina, no es sólo árabe o islámica, es amazigh (bereber), es magrebí y es africana. La entrevista con Rania Benzina, integrante de la Asociación Tunecina de Mujeres Demócratas, expone la complejidad del entramado político y la lucha contra el patriarcado de las mujeres en Túnez, así como una cuestión vital: ¿qué significa ser una mujer en Túnez? La respuesta que se está articulando evidencia un proceso de redefinición política.
\end{abstract}

\section{Palabras Clave}

Feminismo islámico; feminismo laico; mujer tunecina; Túnez.

\footnotetext{
1 Indira Sánchez Bernal es profesora- investigadora del Departamento de Ciencia Política y Relaciones Internacionales del Tecnológico de Monterrey, Campus Ciudad de México. Asimismo, este artículo se realizó con el apoyo de Alejandra Ortega, responsable para Países Árabes, África y Asia y OIT en la Secretaría Internacional y Cooperación, de la Confederación Sindical de Comisiones Obreras de España quien también es una luchadora social, y que, sin su apoyo, no hubiésemos podido acceder a Rania.
}

Esta obra está sujeta a la Licencia Reconocimiento-NoComercial-CompartirIgual 4.0 Internacional de Creative Commons. http://creativecommons.org/licenses/by-nc-sa/4.0/ 


\title{
Indira Sánchez Bernal
}

\begin{abstract}
The struggle of Tunisian women since the 1980s resulted in a divide between Islamic feminism and secular feminism. Secular feminism criticizes the idea that the political and social emancipation of women could be based on religion, because religion subumes women's role in society. In contrast, Islamic feminism maintains that the fight against patriarchy should be framed within Islam because religion has provided women the elements to be subjects of law and politics. Since 2011 protests, the dichotomy between both sides has grown deeper, especially after the Al-Nahda party came to power, and the reconstruction of Tunisian women`s identity has become a debate among women. Tunisian women are not only Arab or Islamic; they are also Berber, Maghreb, and African. The interview with Rania Benzina, a member of the Tunisian Association of Democratic Women, exposes the complexity of the political framework and the struggle against the patriarchy in Tunisia, as well as a vital question: what does it means to be a woman in Tunisia? Women's answer to this query is, therefore, a process of political redefinition.
\end{abstract}

\section{Keywords}

Islamic feminism; secular feminism; Tunisian woman; Tunisia.

\section{Rania Benzina en un espacio liminal fronterizo}

Diez años han pasado desde que el mundo tuviese noticias de las protestas sociales en el Norte de África y en Asia Sudoccidental (región conocida eurocéntricamente como Medio Oriente y Norte de África), manifestaciones que despertaron sueños de emancipación social, de equidad, de igualdad y de mejoras en la calidad de vida de las poblaciones. Las protestas, en su gran parte, devinieron en la caída de gobiernos considerados como autoritarios: Zine ElAbidine Ben Ali (1987-2011) en Túnez, Hosni Mubarak (1981-2011) en Egipto, Muamar el Gadafi (1969-2011) en Libia; en reformas constitucionales como fueron los casos de Túnez, Egipto y Marruecos o incluso en guerras civiles como las sucedidas en Libia, Siria y Yemen. Las protestas dignificaron a las poblaciones, generaron procesos de solidaridad y visibilizaron muchos de los problemas sociales que vive esta región del mundo y que habían sido ocultados por poderes gerontocráticos, militares y policiales: desempleo, desigualdad social, persecución de la oposición política, abuso de poder, violencia contra las mujeres, crisis de salud y de educación.

Las protestas emergidas en la zona del Norte de África desde noviembre de 2010 en Gdem Izik (Sahara Occidental) han sido constantes hasta el año 2020 y se han ido transformando en movimientos más organizados y con una mayor claridad en sus demandas. Difícil es pensar hoy en día en protestas árabes, porque los imazighen (bereberes), los kurdos, los coptos, entre otros grupos, han salido a las calles y han hecho visibles que ellos y ellas han estado en las protestas y que las manifestaciones no pertenecen a una sola identidad étnica o religiosa. Asimismo, las mujeres en toda la región han hecho patentes las dinámicas patriarcales sostenidas desde el mismo Estado, y han denunciado sus expresiones cotidianas en los grupos familiares, estudiantiles, o incluso en las movilizaciones sociales. 


\section{Entrevista a Rania Benzina. La dicotomía del proceso emancipatorio político y social de las tunecinas}

Las manifestaciones han devenido en una sociedad en movimiento y sin duda la participación de las mujeres es más frecuente, tanto de aquellas que se denominan feministas y se definen como laicas, como de las feministas islámicas, cuya agencia es analizada por Saba Mahmood en su artículo "Feminist Theory, Embodiment, ant the Docile Agent: Some Reflections on the Egyptian Islamic Revival" (Mahmood, 2001).

Los procesos han sido diferentes en cada uno de los países integrantes de la región: Marruecos, Túnez, Libia, Egipto y Argelia, especialmente si nos referimos a los tiempos, a sus agentes y a las formas. Uno de los países que ha sido calificado como "ejemplo de apertura" (Lema, 2018,12) es precisamente Túnez y mucho se ha dicho respecto a que es el país que mejor ha logrado cambios políticos después de las protestas del año 2011, aunque no sin obstáculos.

La "apertura" política tunecina puede caracterizarse por la transparencia en las elecciones, el incremento de la participación de jóvenes en política y el logro de la paridad de género en muchos espacios de la vida pública. Las tunecinas se han convertido en un ejemplo de lucha para las mujeres norafricanas por ser las que más han avanzado en la obtención de logros ciudadanos y de adjudicación de espacios públicos. No obstante, se encuentran inscriptas en un debate dicotómico y binario, debido a las diferencias existentes entre los grupos y las agendas para lograr la emancipación política, laboral y social de las mujeres. Ciertamente se ha avanzado hacia la paridad de género, pero es una narrativa que ha sido impulsada también por el Estado, de ahí que se considere que la paridad es parte del feminismo de Estado, aunque también existen movimientos desde abajo que han luchado por ese propósito y que rebasan la esfera estatal.

En el presente artículo realizo una entrevista a Rania Benzina, integrante de la Asociación Tunecina de Mujeres Demócratas, quien se considera a sí misma una mujer tunecina feminista y quien a través de su voz explica cómo ha sido su experiencia de lucha como feminista en Túnez y en España.

Conocí a Rania a través de la Dra. Alejandra Ortega, responsable para Países Árabes, África y Asia y OIT en la Secretaría Internacional y Cooperación de la Confederación Sindical de Comisiones Obreras de España. Con la Dra. Alejandra, a quien conozco desde el año 2005, hemos tenido varias colaboraciones, incluido un conversatorio sobre la situación de las mujeres jornaleras en Huelva, España. Alejandra Ortega se ha mantenido en constante lucha por mejorar las condiciones laborales de las mujeres africanas. Con ella comenté el interés en mostrar diferentes luchas de mujeres en África e inmediatamente surgió el nombre de Rania Benzina, quien desde España se ha dado a la tarea de desmitificar la percepción eurocéntrica que se tiene sobre las mujeres tunecinas mediante conversatorios y encuentros culturales y quien además, es una tunecina que defiende el matrimonio mixto en Túnez e intenta generar diálogos a través de la idea del mestizaje.

Contacté a Rania Benzina mediante correo electrónico y se mostró muy interesada en atender la entrevista porque consideraba que las mujeres latinoamericanas entendemos mejor la lucha de las mujeres norafricanas debido a que compartimos 


\section{Indira Sánchez Bernal}

historias similares (colonización, mestizaje, liminaridad, patriarcado). Puedo decir que he estudiado por más de veinte años la región del Norte de África, especialmente los cambios políticos en Marruecos y los movimientos sociales en ese país y por primera vez, al entablar el diálogo con Rania, me sentía parte de una historia compartida, porque intercambiamos visiones, sentimientos y luchas similares, pese a ser ella tunecina y vivir en España y yo una mexicana residiendo en la Ciudad de México.

La intención de entrevistar a Rania radica en escuchar la voz de una mujer que ha sido parte de la lucha feminista en Túnez desde 2011. La entrevista se realizó el día 27 de noviembre del 2020 y resultó una conversación relajada vía Zoom durante la que compartimos historias comunes en un diálogo constructivo que generó confianza mutua.

Rania radica en España, desde donde se considera una embajadora de Túnez que intenta cambiar la percepción de las mujeres europeas, quienes en su mayoría consideran a las "mujeres árabes", invariablemente vinculadas a la religión islámica, como vulnerables y, en consecuencia, víctimas, en un discurso que ella identifica con el feminismo hegemónico. A lo largo de la entrevista, nos podemos percatar cómo Rania se sitúa en un espacio liminal fronterizo, siendo una mujer tunecina en España, quien defiende su identidad tunecina, pero se moviliza en un entorno epistémico eurocentrado.

La entrevista permite entrever algunas facciones de la lucha feminista laica en Túnez, la cual se desvincula de la religión, en tanto el Islam, en términos de Rania, avala la complementariedad entre el hombre y la mujer, pero no la equidad, como es visible en el proyecto de Ley sobre la igualdad en sucesiones del año 2018 (Loi sur l'égalité successorale/قانون المساواة في الميراث (قاث) 2. A lo largo del diálogo se pueden identificar dos vertientes feministas en Túnez: la islámica y la laica, y el entramado que se genera al momento de reconstruir una identidad.

El feminismo laico en Túnez se mueve entre el pensamiento de la segunda y la tercera ola del feminismo euroestadounidense. De allí se retoman las ideas de igualdad de oportunidades entre hombres y mujeres, el incremento de derechos civiles y ciudadanos en el espacio público, la libertad de elección y de ser elegida y comienza apenas a definirse como un movimiento en contra del sistema de dominación patriarcal. Se le concibe como laico porque sus voceras consideran que la religión islámica subordina a la mujer en su imagen, en las estructuras organizativas y especialmente, en el espacio de la moral y de la sexualidad. Las feministas laicas (Alya Baffoun, Asma Belkhodja, Sana Ben Achour, Sophie Bessis, Noura Borsali, Majida Boulila, Dorra Bouzid, Latifa Lakhdar, Amina Tyler) consideran que el Islam no puede ser una herramienta de emancipación de las mujeres, y es un feminismo que aún se encuentra en diálogo con el poder estatal. Esta afirmación de que el marco legal y político de Túnez para la igualdad de género es excepcionalmente ilustrado y "moderno" es uno de los mitos más poderosos

\footnotetext{
2 Proyecto de ley propuesto por el presidente Béji Caïd Essebsi en el año 2018.
} 


\section{Entrevista a Rania Benzina. La dicotomía del proceso emancipatorio político y social de las tunecinas}

sobre el feminismo en la política tunecina. Los análisis sobre el empoderamiento de las mujeres y los logros feministas se centran abrumadoramente en el derecho de familia tunecino, en particular el Código de la Condición Personal (CPS). Al hacerlo, han reproducido la fusión del feminismo tunecino con el feminismo de Estado, un proyecto de Estado clientelista y disciplinario que ha buscado "levantar" y "modernizar" el género (Yacoubi, 2016, 255).

Por otro lado, el feminismo islámico, muchas veces no concebido por sus integrantes como tal, lucha por la emancipación de la mujer dentro de los límites del aparato religioso y argumenta que la sumisión de la mujer es hacia Allah y no hacia los varones.

De igual modo, feministas islámicas como Olfa Youssef, critican al feminismo laico porque éste rechaza a la religión, que es una parte muy importante de la identidad de las mujeres musulmanas y defienden que en el Corán se encuentran prescritos los derechos de las mujeres, sólo que se lo ha interpretado desde una visión masculina y en consecuencia luchan por un proceso de interpretación femenina del texto sagrado.

El feminismo islámico debe contextualizarse en el movimiento más amplio del Islam reformista. El movimiento reformista en el Islam consiste en un creciente número de sabias y sabios que han llamado la atención acerca de interpretaciones alternativas del Islam mediante sus orientaciones teóricas y sus acercamientos prácticos (Salem, 2014, 117)

Así, tanto el feminismo islámico como el laico se encuentran entrampados en los márgenes de un debate dicotómico sobre qué camino deben de seguir las tunecinas para convertirse en ciudadanas de pleno derecho.

Con la finalidad de contextualizar esta entrevista, se presenta un panorama de la historia de las luchas de las mujeres en Túnez, especialmente de aquellas que se consideran feministas, como un acercamiento a experiencias norafricanas que permitirán la construcción de puentes con otros espacios de enunciación, especialmente desde América Latina y desde México, que es desde donde se escribe el presente texto.

\section{La lucha de las mujeres tunecinas en contexto}

Túnez, en comparación con otros países de la región, ha sido un país que desde su independencia abogó por los derechos de las mujeres. Mientras que, en Marruecos en el año 2004 las mujeres apenas lograban la modificación del Estatuto Personal y el Código de la Familia, en Túnez desde 1956 (año de la independencia) se aprobaba el Código del Estatuto Personal mediante el cual se regulaba el divorcio para hombres y mujeres y se abolía la poligamia. Dichas decisiones no fueron casuales, en realidad formaron parte de los sueños modernizantes y reformistas del presidente Habib Bourguiba, quien entonces deseaba consolidar un Estado de características eurocéntricas: "Burguiba, en efecto, fue fiel a la corriente reformista 


\section{Indira Sánchez Bernal}

que empezó a germinar desde finales del siglo XIX y principios del XX, animada por las elites tunecinas, formadas en Francia, generalmente" (Farhat, 2005, 45). El nacionalismo árabe sin duda se fundamentó en las ideas de los nacionalismos europeos y ello produjo desde su comienzo, elementos de contradicción como la disputa entre la religión y el Estado, la idea de progreso, la urbanización y la modernización.

Gran parte de los así llamados nacionalismos árabes se mostraban como una ideología anticolonial porque defendían la independencia y la soberanía de los territorios; sin embargo, al mismo tiempo, reprodujeron la matriz colonial moderna. Las leyes permitían un campo de acción a las mujeres en el espacio privado, pero las separaban del poder como sujetas políticas. Es Importante señalar entonces, que el Código del Estatuto Personal exponía al gobierno tunecino como progresista y parte de dichas acciones se mostraban a través de las campañas de escolarización para las niñas ${ }^{3}$, impulsadas por el reconocido sindicalista Tahar Haddad (plasmadas en su obra 'Notre femme dans la chariaa et la religión'4). Esto no fue muy diferente de lo propuesto por Gamal Abdel Nasser en Egipto. Desde la década de 1950 y hasta 1980, el impulso que se dio a las libertades de las mujeres en Túnez y en Egipto se generó como parte de las políticas públicas estatales, las cuales definían al sujeto femenino nacional -cómo ser una mujer tunecina o egipcia-; lo cual implica que los derechos reconocidos -"otorgados"- a las mujeres provenían de una política estatal y desde arriba, reforzando así el papel tutelar del Estado sobre las mujeres.

Tahar Haddad consideraba que eran necesarias una serie de reformas para darle a las mujeres derechos fundamentales: el derecho de estudiar, la libertad de elegir su cónyuge, el derecho de participar en la vida pública. Apeló a la liberación del velo (él lo consideraba como una tradición citadina por lo que estaban exentas las mujeres rurales) y eso habría de acompañar la evolución de la sociedad (Mahfoudh-Draoui, 2018, 44). ${ }^{5}$

El pensamiento de Tahar Haddad coadyuvó a que las mujeres, especialmente en el contexto urbano, se involucraran en la vida social y política del país, como fue el caso de Cherife Messadi, quien fuese Secretaria General del Sindicato de la Enseñanza Técnica y Profesional de 1947 a 1968. Aunque con presencia de mujeres en sus filas, los sindicatos no fueron críticos a las políticas gubernamentales $\mathrm{y}$, de hecho, Cherife es poco conocida, ya que la vida política en Túnez está francamente masculinizada. La proyección de las mujeres en Túnez, como parte de un Estado moderno, generaba al interior muchas contradicciones, especialmente porque era un proyecto

\footnotetext{
${ }^{3}$ Las campañas de escolarización lograron que, para el año de 2018, la tasa de alfabetización de la población fuese de $89 \%$ para los hombres y $74.2 \%$ para las mujeres. De acuerdo a Emmanuel Todd, quien hace un estudio prospectivo en su obra Después del Imperio: ensayo sobre la descomposición del Sistema Norteamericano, uno de los factores de la transición demográfica, es el aumento de la escolarización en hombres y mujeres, y esto ha influido también en la disminución de las tasas de fecundidad y en la inserción de las mujeres en el espacio laboral: "Cuando los hombres, o más exactamente las mujeres, saben leer y escribir, comienza el control de la fecundidad" (Todd, 2003, 29).

${ }^{4}$ Haddad, Tahar (2018). Notre Femme dans le charia et la societé. Túnez: Nirvana.

${ }^{5}$ Traducción realizada por la autora.
} 


\section{Entrevista a Rania Benzina. La dicotomía del proceso emancipatorio político y social de las tunecinas}

progresista y urbanocéntrico, vinculado al llamado "occidente" y con una tendencia laica, lo cual no necesariamente era bien recibido por la población que tenía una fuerte vinculación con el Islam. Para estos sectores de la población, se trataba de proyectos elitistas, clasistas y que no abordaban los problemas de las clases populares. Esta construcción de dos feminismos con características binarias y excluyentes terminó por reforzar la separación entre las mujeres que apoyaban la agencia islámica y las mujeres que se encontraban en contra de dicho proceso, lo cual será abordado más adelante.

Las mujeres consolidaron algunas agrupaciones como la Unión Nacional de las Mujeres de Túnez (fundada en 1956), la Asociación Tunecina de Mujeres Demócratas (1989), la Asociación de Mujeres Jueces, así como el Centro de Investigación, Documentación e Información sobre la Mujer (muy activo en la década de los años noventa) y, con el paso de los años, las tunecinas obtuvieron el derecho de adoptar, de llevar el control de su fertilidad e incluso de abortar, ya que en Túnez la interrupción voluntaria del embarazo, antes de los tres meses de gestación, es legal desde 1973. De hecho, algunos reclamos interseccionales comenzaron a hacerse oír desde los años setenta, ante la discriminación por sexo y la discriminación de clase en el espacio laboral, especialmente en la Comisión de Mujeres de la Unión Tunecina del Trabajo, sindicato histórico y el más representativo en el país.

Para Dorra Mahfoudh-Draoui 6 , profesora asociada de sociología y consejera de ciencias sociales de la Universidad de Túnez, es durante los años ochenta, específicamente el 8 de marzo de 1982, que surge el feminismo tunecino, porque las mujeres se concibieron como sujetas políticas a través de la demanda de mejoras en las condiciones laborales (la regulación de la maternidad, la dignificación en el trabajo y el acceso a servicios sociales).

El gran problema de la época, era que los empleadores, siempre varones, reproductores de un pacto patriarcal, no permitían que las mujeres se sindicalizaran, por lo que lograrlo se convertiría en una bandera de lucha. No habría de ser hasta el año 2014, que las mujeres trabajadoras alcanzaron plenos derechos con la reforma sindical, la cual ha estado muy vinculada a la izquierda tradicional en Túnez ${ }^{7}$.

Las mujeres han estado presentes en la vida económica de Túnez y desde la década de 1980 de manera más plausible,

[...] el porcentaje de inserción de las mujeres en la vida activa ha aumentado y, han podido acceder al mercado laboral especialmente en sectores como la

\footnotetext{
6 En la entrevista para BBC Mundo el 17 de enero de 2017, consultar en https://www.bbc.com/mundo/noticias-internacional-38646934

7 Para mayor información sobre sindicalismo se puede consultar la Tesis doctoral de Ortega Fuentes, Alejandra (2015), El movimiento sindical en Túnez y en Egipto: colaboración, disidencia y renovación, (Tesis Doctoral inédita). Departamento de Estudios Árabes e Islámicos, Facultad de Filosofía y Letras en https://repositorio.uam.es/bitstream/handle/10486/669590/ortega_fuentes_alejandra.pdf?sequence= 1
} 


\section{Indira Sánchez Bernal}

agricultura, la industria, la sanidad y el transporte.... En 1960 la mujer solo representaba 5\% de la población activa mientras en 1980 llegó a alcanzar el 20\% (Montoro, 1992).

La doble jornada laboral -trabajo doméstico no remunerado y empleo remuneradoes una realidad para muchas de ellas.

A la par, en la década de los años ochenta e impulsadas por el triunfo de la Revolución Islámica en Irán (1979), así como la presencia del Frente Islámico de Salvación en Argelia (1988), agrupaciones y asociaciones islamistas manifestaron su oposición a los derechos reconocidos a las mujeres en el Código del Estatuto Personal. Sin embargo, ni el presidente Habib Bourguiba (1957-1987) ni posteriormente, el presidente Ben Ali (1987-2011) dieron cabida durante sus administraciones a sus reclamos, no tanto por defender el Código del Estatuto Personal, sino porque en todo el Norte el islamismo de África se estaba posicionando como la oposición a los gobiernos en turno, ${ }^{8}$

En Túnez, la principal oposición política durante el gobierno de Habib Bourguiba provino de la izquierda de tendencia socialista, y no fue hasta 1980, ante la ineficacia de cambio político, que los islamistas como la Asociación Jama'a Islamiya (Asamblea Islámica), el Movimiento de Tendencia Islámica (antecedente del actual partido Al Nahda) y el posterior Partido de la Liberación islámica, devinieron en la principal oposición al régimen. Sin embargo, se les negó la puerta de entrada al juego político, porque no se les permitió participar en las elecciones, de ahí que se convirtieran en una alternativa viable después de la caída de Ben Ali, tras las protestas del año 2011. Como movimiento sociopolítico de contestación y de cambio, el islamismo se inscribe en la crisis de las ideologías de la modernidad y del Estado-nación periférico, ante la incapacidad de las capas sociales dirigentes para crear un sistema de valores y un modelo de modernización específicos de acuerdo con la propia identidad cultural, así como un cuadro institucional de integración de los conflictos. Todo ello, en el marco del crecimiento de las desigualdades sociales, la marginación y la exclusión (Lacomba, 2000, 95).

Los grupos islamistas fueron contenidos, se les negó el acceso a la arena política del partido Al Nahda y como sostiene Miguel Hernando de Larramendi:

Ben Ali se vio obligado a modificar su estrategia frente al movimiento islamista tunecino optando por la vía de la confrontación: la solicitud de legalización del partido de la Nahda fue definitivamente rechazada y los dirigentes de la organización comenzaron a ser perseguidos y encarcelados siendo acusados de conspirar contra la seguridad del Estado. La débil oposición legal aceptó las

\footnotetext{
${ }^{8}$ Muchas son las similitudes que vive el Norte de África, especialmente después de los procesos independentistas, porque la consolidación de sus estados nacionales implicó el debate sobre las formas de gobierno a adoptar, así como sus modelos económicos: socialistas, capitalistas o islamistas que resultaron en fórmulas diversas. Marruecos estableció una monarquía oficialmente islámica de modelo capitalista; Argelia, una república socialista con tintes islámicos; Libia, una Yumhuriyya (república) ghadafiana; Egipto, una república semi socialista islámica y Túnez, una república capitalista de tendencia modernista. En la mayoría de los casos, los sectores de tendencias islamistas fueron marginados por los gobiernos, por lo menos hasta finales de la década de 1980.
} 


\section{Entrevista a Rania Benzina. La dicotomía del proceso emancipatorio político y social de las tunecinas}

limitadas posibilidades de inserción en el sistema que le ofrecía el régimen prestando a cambio su apoyo tácito a la manera de gestionar el dossier islamista (Larramendi,2000: 127).

De ahí que Al Nahda se convirtiera en la oposición más fuerte en Túnez y que algunas mujeres militantes de esta agrupación sostuviesen a la religión como una forma de agencia para las tunecinas, porque el Islam representaba un modo de resistencia a las estructuras del poder moderno patriarcal.

Desde la llegada al poder en 1987, el presidente Ben Ali, a pesar de haber suscrito la defensa de los derechos humanos en el país frente al contexto internacional, prosiguió la persecución en contra de los islamistas y a partir de 1995 el régimen comenzó a mostrar un perfil más coercitivo, extendiendo la represión a cualquier forma de disidencia política. Por ello, las mujeres islamistas comenzaron a defender la identidad islámica como una forma de expresión y de defensa de la libertad y expusieron que la causa del deterioro del escenario político se debía a que el gobierno se había alejado de las pautas islámicas del buen gobierno musulmán.

Las islamistas en Túnez defendían que el principio de igualdad estaba resguardado por el Islam y por el Corán y que lo que se debía de hacer era la feminización de la Ijtihhad (la interpretación religiosa) e instaban a oponerse al Niswaniya (feminismo radical) porque de acuerdo a su ideología, el hombre y la mujer son complementarios y el feminismo radical (feminismo laico) los pone en competencia. Asimismo, criticaron a las feministas tunecinas por seguir un feminismo hegemónico modernista y modernizante, el cual se contrapone al Islam y las coloca en un plano desigual frente a mujeres europeas, prácticamente en una situación de dominación colonial y, catalogan a dicho movimiento como asimilacionista, como una mímica de lo europeo. Una gran representante del feminismo islamista es Olfa Youssef, quien es profesora universitaria en la Facultad de Artes y Humanidades de la Universidad de Manouba y quien ha realizado un trabajo profundo y arduo sobre la polisemia coránica y con base en la semiótica y la filosofía ha deconstruido el discurso hegemónico de la interpretación del texto coránico y ha investigado su ambigüedad (Youssef, 2007).

Las feministas islámicas dominan el Corán y se enfrentan a los fundamentalistas en su propio terreno, refutando sus argumentos con los textos sagrados y sus interpretaciones. Son partidarias de una lectura abierta del Corán que se adapte al mundo actual. Para algunas teóricas, el feminismo islámico representa la única posibilidad que tienen las mujeres musulmanas de salir de la doble encrucijada del islam y del feminismo. Ofrece una manera de conciliar sus creencias e identidad religiosa y la lucha por la igualdad de sexos (Bueno, 2012, 29).

La situación política en Túnez para los años noventa continuaba reproduciendo términos binarios, excluyentes entre sí: las feministas laicas y las islamistas.

El feminismo islámico critica el proceso de occidentalización porque borra la identidad islámica de las mujeres y atenta contra la unidad básica familiar y hay una desvalorización de la pareja. Para las islamistas, la liberación de la mujer en Túnez 


\section{Indira Sánchez Bernal}

puede ser concebida como una lucha contra el patriarcado desde el Corán. En cambio, las feministas laicas argumentan que no puede haber igualdad mientras las mujeres musulmanas tengan una actitud positiva ante la desigualdad y la jerarquización presente en el Corán. Estas dos percepciones, se han hecho cada vez más profundas y se han polarizado especialmente después de las protestas del año 2011. Sin embargo, hay que subrayar que ambas tendencias, con diferentes estrategias de lucha, han concebido a la mujer tunecina como un sujeto de derecho y como una ciudadana partícipe de la vida política.

Para el año 2011, las contradicciones sociales en las que vivía Túnez se hicieron presentes, especialmente, después de la crisis económica del año 2008 y los 24 años de estancia en el poder de Ben Ali, que expusieron las dinámicas de corrupción, clientelismo, nepotismo y neopatrimonialismo que vivía la república. La familia del presidente era quien controlaba un porcentaje sustancioso de importantes segmentos de la economía: hoteles, bienes raíces, telecomunicaciones y automóviles.

No hay que olvidar que Ben Ali terminó por instaurar un Estado policial y las protestas no se hicieron esperar. Mujeres y hombres salieron a las calles, tomaron el espacio público y lograron que el presidente saliera del país, huyendo hacia Arabia Saudita. Ese es el momento de lo que ya en otros estudios ${ }^{9}$ hemos llamado el inicio de las protestas árabes; sin embargo, para entonces, los que estudiábamos aquella región desde Latinoamérica cometíamos algunos errores: focalizábamos nuestro estudio, muchas veces en el "despertar de la sociedad civil", homogeneizábamos lo árabe como característica de la región; invisibilizábamos el papel de las mujeres en las protestas y nos centrábamos en el estudio de los movimientos islamistas al ser éstos los que arribaban al poder político. Hoy 2021, sabemos que las protestas, si bien no cambiaron por completo los poderes políticos, demostraron que la mayor parte de los países de la región no pueden ser enmarcados bajo la categoría de "árabe", que además de las protestas por la baja calidad de vida o el desempleo, las mujeres luchaban por obtener una mejora democrática, pero además expresaron su desacuerdo contra la violencia y la desigualdad social en la que vivían.

La participación de las mujeres en las protestas en Túnez estuvo presente desde el principio, en las marchas, en los debates, en las huelgas; recordando que su acción política en Túnez ha sido constante. Muchas organizaciones sindicalistas salieron a las calles y además de exigir la salida de Ben Ali, promovían la equidad de género. Es preciso mencionar que La Asociación Tunecina de las Mujeres Demócratas desde los años noventa intentó desmarcarse del feminismo de Estado y criticó abiertamente la actitud del régimen de Ben Ali hacia las mujeres, porque las usaba para mejorar su imagen al exterior, pero no avanzaba de ninguna forma en una política de mayor

\footnotetext{
9 Ver: Western, W., Galindo, A. \& Sánchez, I. (2014); Western, W. \& Galindo, A. (2018) y Mesa Delmonte, L. (2012).
} 


\section{Entrevista a Rania Benzina. La dicotomía del proceso emancipatorio político y social de las tunecinas}

igualdad. La Asociación Tunecina de las Mujeres Demócratas tuvo una gran presencia en la promulgación de la Constitución, porque retomó y defendió recomendaciones que venían de otras asociaciones de la sociedad civil que luchaban contra la violencia a las mujeres, el matrimonio infantil forzado, así como la paridad de género.

A diferencia de lo que sucedió en Marruecos o en Egipto, en donde las mujeres salieron a las calles sin obtener respuestas a sus demandas, porque los hombres decían que primero estaba la democracia, en Túnez las mujeres comenzaron a ganar terreno y a definir los caminos emancipatorios políticos y sociales, sin embargo ello les generó un reto mayor porque el debate se profundizó entre el feminismo laico y el islamista al momento de plantearse la Reforma Constitucional, cuyo debate inició después del año 2011, y finalmente, se concretó en 2014.

Las islamistas, proponían que en la nueva Constitución hubiese un artículo que posicionaba a la mujer como complemento del hombre en la familia y su socia en el desarrollo del país. Las protestas de las feministas laicas no se hicieron esperar, porque consideraban dicha reforma como un retroceso en los derechos de las mujeres en Túnez; por lo que se realizaron campañas de información en las universidades, en las escuelas y en las calles, logrando finalmente que ese artículo no se incluyera.

Las islamistas no se dieron por vencidas y lograron que en el artículo $7^{\circ}$ de la Constitución quedara plasmado lo siguiente: "la familia es el núcleo de la sociedad y el Estado tendrá la obligación de protegerla". También se aclara en el artículo 21 que, "los ciudadanos y ciudadanas tienen los mismos derechos y deberes y son iguales ante la ley, sin ningún tipo de discriminación y que el Estado garantizará a los ciudadanos y ciudadanas los derechos y las libertades individuales y colectivas y les proporcionará las condiciones de una vida digna". ${ }^{10}$

Tanto las islamistas como las feministas laicas terminaron por reforzar la autoridad del Estado, en la medida que las demandas de los dos grupos quedaron trianguladas por el reconocimiento del Estado.

Después de la aprobación de la Constitución en 2014, la polarización se ha vuelto mucho más profunda especialmente bajo la presencia de islamistas en el poder que debaten códigos morales de corte religioso y los procesos de modernización. Pese a ello, las mujeres en Túnez han logrado obtener cuotas de paridad en los partidos políticos y en el Parlamento. En 2017, se eliminó la reglamentación del año 1973 que prohibía a las mujeres contraer matrimonio con hombres de otras religiones -los llamados matrimonios mixtos-11, y actualmente, la lucha se centra en la obtención

10 Ver el proyecto de la Constitución tunecina de 2014 en español en https://www.constituteproject.org/constitution/Tunisia 2014.pdf?lang=es

11 En Túnez como en otros países cuya religión oficial es el Islam, sólo los hombres podían contraer matrimonio con mujeres de diferente religión al Islam, porque son ellos los que transmiten la cultura. A las mujeres se les prohibía casarse con hombres que no fuesen musulmanes y aquellos que tuvieran otra religión debían abrazar el Islam. 


\section{Indira Sánchez Bernal}

de la igualdad jurídica con respecto a la herencia, ya que, en el Corán, en la Sura (4, 11), se especifica que el hombre debe heredar el doble que la mujer.

Ciertamente, existen diferentes tipos de luchas de mujeres en Túnez y las respuestas a preguntas básicas sobre: ¿cómo ser mujer en un país musulmán?; ¿cómo ser una mujer no árabe en un país que se define oficialmente como árabe?; si eres laica, ¿cómo ser respetada en términos de minorías?; ¿cómo definir la identidad de la mujer tunecina?; ¿se puede ser ciudadana tunecina y a la vez musulmana?; seguir un feminismo ilustrado, entiéndase hegemónico, ¿no ha sido la mejor justificación para generar intervenciones desde el exterior?, aún no están respondidas. Esto se debe principalmente a que estamos frente un camino bifurcado y binario: por un lado, el feminismo laico representa a una parte muy importante de las mujeres citadinas, de clase media, educadas y que optan por un feminismo no necesariamente hegemónico, pero separado de la religión y, por otra parte, el islamismo representa de manera muy convincente a las mujeres que habitan en zonas rurales y que consideran que el Islam es un camino de emancipación. Sin duda, el debate está en ciernes.

Conceptos como capitalismo, democracia, colonialismo, estatismo y patriarcado se ven envueltos en un debate profundo: ¿es el feminismo laico tunecino una copia del feminismo hegemónico occidental?; ¿el asimilacionismo, es una fuente epistemicida porque no critica el capitalismo, ni la democracia, ni la matriz de poder colonial? o bien, ¿el feminismo islámico y su defensa de la complementariedad entre hombres y mujeres, invisibiliza el dominio patriarcal y justifica la jerarquización y la desigualdad?; ¿es la polarización entre estos dos campos lo más fructífero para la reconstrucción de la identidad de la mujer tunecina?

Muchos interrogantes quedan sin responder en este texto porque simplemente no existen respuestas definitivas, sino que se van dando de acuerdo con las experiencias de lucha de las mujeres tunecinas, a través de las voces que levantan y de sus disputas, en donde las identidades no son inamovibles, sino que son multifacéticas y se van construyendo bajo un entramado complejo.

\section{Rania Benzina, feminista y mediadora social}

Rania Benzina es una mujer tunecina de 39 años, integrante de la Asociación Democrática de Mujeres en Túnez. Me compartió su vida como mujer feminista que trabaja en los últimos años en España. Desde la diáspora, defiende un feminismo laico en Túnez.

Actualmente, trabaja en la Comisión Española de Ayuda al Refugiado, pero se considera una embajadora de su país que intenta desvictimizar a las mujeres tunecinas en Europa y apela al feminismo laico tunecino para contrarrestar el feminismo islámico.

Rania, nos cuenta cómo ha sido la lucha por la identidad de las mujeres en Túnez desde las protestas del año 2011: "Si tú te das cuenta, Túnez [el mapa] tiene la forma 


\section{Entrevista a Rania Benzina. La dicotomía del proceso emancipatorio político y social de las tunecinas}

de una mujer llevando una luz en su mano y esto nos ha dado a las mujeres mucha fuerza, pero no sólo eso, nos ha hecho pensar en nuestra identidad, nuestra identidad bereber y no sólo árabe o islámica. Desde que llegaron los islamistas al poder han intentado borrar nuestra historia de lucha y nos han querido imponer una identidad con la cual no estamos de acuerdo, ello ha encendido el fuego en las mujeres tunecinas y nos ha hecho luchar más fuerte por el logro de nuestros derechos y nos ha reafirmado como mujeres. Esta lucha no ha sido del todo auténtica, porque nos han apoyado hombres, nuestros padres, pero luchamos en términos de identidad, ya que la llegada al poder ha dividido al pueblo tunecino en dos: los islamistas y los tunecinos laicos. Somos musulmanes, pero no tenemos la misma interpretación que hacen ellos y ellas de la religión. La religión es parte de la identidad, pero no con la interpretación de los islamistas, ellos nos quieren quitar los derechos que hemos ganado desde hace cincuenta años".

En este sentido, Rania explica el proceso de devenir feminista en Túnez: "Cada mujer tunecina se hace feminista desde muy pequeña. Recuerdo que cuando tenía cinco años abogaba ya por mi hermana. En mi familia se notaba cómo al hermano mayor le daban lo mejor, le daban más comida y mi padre solía decir: 'trae esto para tu hermano', y yo reclamaba diciendo: 'él tiene piernas y manos y puede hacerlo solo'. Ser feminista no sólo se trata de formar parte de asociaciones, sino de luchar contra las prácticas cotidianas, contra las violencias que se viven en la familia, por pequeñas que sean. Se ha subrayado el papel de las feministas que salen a las calles, pero hay chicas que están luchando de manera diferente, de una forma increíble, desde la cotidianidad. Yo, por ejemplo... en mi casa he luchado y he conseguido muchas cosas, porque mi padre está abierto en algunas cosas, pero en otras es tradicional. Tuve que luchar para elegir pareja porque formé un matrimonio mixto (antes prohibido en Túnez); para vestirme como deseo vestirme... en Túnez siempre se vive con una doble personalidad, como alguien que respeta la cultura, pero al mismo tiempo debes generar estrategias para hacerte respetar, para imponerte en el trabajo, todos los días y aunque no lo creas, esto es agotador... Incluso... en el ámbito de la sexualidad el tema se vuelve complicado, bajo la ley puedes abortar o comprar métodos anticonceptivos, pero en la práctica hay farmacéuticos y médicos que no te venden el medicamento o te juzgan. En la práctica, no somos libres socialmente hablando, es un peso que siempre vas cargando. Hay chicas que se rinden, y se apegan al canon islámico. Hay padres y madres que te apoyan, pero en otros casos no, también las madres están luchando".

Rania reconoce que, en su caso, como mujer ha tenido privilegios en comparación con otras mujeres, privilegios de clase, pero es por eso por lo que lucha, para sensibilizar a otras mujeres. "Yo nací en la capital y mis padres son profesores, mi madre era una mujer trabajadora y al mismo tiempo revolucionaria, como jubilada se dedica a la poesía con intereses políticos, yo aprendí a luchar porque vi como mi madre luchaba. Tanto mi padre como mi madre nos alentaron a estudiar y nos decían que primero debíamos educarnos y que el matrimonio lo pensáramos como lo último. Mi padre tuvo una visión diferente también porque vivió en Europa. Vivió 


\section{Indira Sánchez Bernal}

mucho tiempo en Noruega y en Suecia y para él el cambio no ha sido fácil... si para las mujeres es difícil cambiar, para los hombres también lo es. Asimismo, nos enseñaron a crecer con responsabilidad y a tener independencia económica. Además, fui una chica aún con más privilegios porque mi madre me llevaba a las reuniones políticas de mujeres que se realizaban en el Club Tahar Haddad. Cada miércoles se leía un libro, abordaban temas concernientes a las mujeres y yo escuchaba, aprendía, a veces no estaba de acuerdo... aún veía tintes tradicionalistas, incluso en mi madre, pero fue cómo descubrí qué quería ser como mujer y lo hacía patente en la escuela. Desde pequeña comencé a buscar la justicia. En Túnez, en las escuelas, los profesores cometen acoso y las estudiantes suelen callarse, pero aprendimos a denunciar, como lo hice en su momento en la escuela. Las mujeres tenemos que aprender a no silenciarnos, ni siquiera entre nosotras mismas. También denunciamos que las mujeres tuviésemos más tiempo de estudio que los hombres. Mientras los hombres terminaban la escuela, nosotros teníamos que tomar dos horas diarias de costura. Nos inconformamos, porque la medida era unilateral y discriminatoria, queríamos tener igualdad. También me di cuenta de mis privilegios, porque mi abuelo tiene una finca en el sur de Túnez y vi los comportamientos diferentes de las mujeres que viven en las zonas rurales, quienes tienen un acceso diferente a la educación, están apegadas al Islam...pienso que la educación es la clave del cambio".

En cuanto a la educación, afirma lo siguiente: "Ciertamente tuve una educación eurocéntrica, porque asistí a una escuela con el modelo francés, pero la educación te permite discernir, hay mujeres en Túnez que aún no tienen acceso a ella. Sólo puedes criticar el dominio eurocéntrico cuando sabes de su existencia y eso lo aprendes en la escuela. Aunque déjame decirte, aprendí a ser mujer no sólo en la escuela o con mi familia, las reuniones de las mujeres en el campo se expresan a través de mucha libertad, cuando hablaban, cantaban y relataban cuentos que implicaban mucha más libertad que las mujeres revolucionarias del Club Tahar Haddad en la capital, donde no se hablaba tanto de sexualidad, mientras que en la finca era un tema recurrente, especialmente en mujeres bereberes. Es allí, donde me di cuenta que las identidades son diferentes y que esa identidad debe reconstruirse en Túnez. Las mujeres del campo, las mujeres bereberes han adquirido la lucha, no por educación...se aprende en lo social. Somos diferentes, pero todas somos mujeres; pero por lo menos debe existir la opción de adquirir educación porque a la mujer bereber se le ha privado de la educación... las abuelas nos han dejado otras estrategias de lucha, pero nosotras hemos adquirido otras... las mujeres bereberes no tienen miedo".

Para Rania la traducción intercultural es una herramienta fundamental de lucha: "Estudié filología española... no sin lágrimas (se ríe), pero la filología me abrió las puertas a un mundo completamente diferente, porque mis primeras experiencias feministas se tradujeron en participación en clubes de cine, círculos de lectura, obras de teatro. La cultura se ha desvinculado de la acción política y esto es un error, la cultura y el arte son parte de la acción política. En la Universidad todavía no formaba parte de las asociaciones feministas. Las asociaciones feministas en Túnez son 


\section{Entrevista a Rania Benzina. La dicotomía del proceso emancipatorio político y social de las tunecinas}

elitistas, no todas podemos participar. Debes de conocer a alguien y es difícil integrarse, lo logré, pero mucho tiempo después. En la dictadura, el arte y la cultura fueron la herramienta política. Otras lenguas incluso te permiten conocer tu propio contexto. Un tiempo trabajé para el Instituto Cervantes como bibliotecaria y conocí los textos feministas de mujeres del norte de África en español... ¿no te parece curioso?, aprendí de mi país en español, los libros escritos por mujeres de la región de Medio Oriente y Norte de África. En Túnez, hace poco tiempo que empezaron a ser distribuidos. A mis manos llegaron autoras como Nawal El Saadawi, Sophie Bessis, Joumana Haddam, Wassyla Tamzali y mi activismo comenzó a ser más consciente, más feminista. Haber leído en español me ayudó, cuando llegué a España, a empezar a dar a conocer el papel de las mujeres en Túnez".

Rania, también explica cómo ha sido su lucha desde la diáspora: "En Europa y en España, en donde vivo desde hace varios años, no se quiere reconocer que en Túnez y en otros países árabes existimos mujeres feministas. Han creado de nosotras una caricatura, representadas siempre por el Islam, por el velo. Nos miran siempre como oprimidas, victimizadas y cuando encuentran a una mujer feminista laica, emancipada... una mujer que lucha, no nos quieren reconocer y es una forma de invisibilizar nuestra historia de lucha y dominarnos bajo el pretexto de la ayuda a la mujer víctima y oprimida por el Islam. Incluso, desde el Master de Género y Diversidad que estudié, invitaron a una joven para que hablara de feminismo islámico y hasta los medios de comunicación llegaron. Para mí, el feminismo musulmán no existe, no puede ser feminismo, la religión y el feminismo no se llevan. A los europeos les viene bien el feminismo islámico. Tenemos varios retos como mujeres tunecinas".

Dichos retos impulsaron a Rania a regresar a Túnez por períodos cortos e inscribirse como militante en la Asociación tunecina de Mujeres Demócratas. La Asociación se constituyó formalmente en 1989, especialmente porque se oponían a las concesiones que se hacían a los y las islamistas por parte del gobierno de Ben Ali, ya que las consideraban contrarias a la lucha histórica de las mujeres. Las mujeres de la Asociación defienden la Convención sobre la eliminación de todas las formas de discriminación contra la mujer y construyeron un centro de apoyo para las mujeres víctimas de la violencia; lograron una ley sobre el acoso sexual y actualmente luchan por el logro de la paridad legislativa: "Realicé la formación en la Asociación y trabajo con las jóvenes, estamos en las manifestaciones del día 13 de agosto, porque el 13 de agosto desde $1956^{12}$ se considera la fiesta de la mujer en Túnez... estamos en contra de los islamistas y tenemos que luchar... no es que no respete el feminismo islámico, pero para mí el feminismo no es compatible con la religión... todas las mujeres de la región, árabes o no, musulmanas o no, en el fondo están dejando el estatus de sumisión, sólo es cosa de rascar un poquito".

El trabajo que tiene Rania en la Comisión de Ayuda al Refugiado no es sencillo, explica: "He tenido que luchar con las jóvenes árabes y musulmanas que llegan,

${ }^{12}$ El 13 de agosto de 1956 se dio la promulgación del Código del Estatuto Personal en Túnez. 


\section{Indira Sánchez Bernal}

porque las chicas españolas, a pesar de que son psicólogas y están capacitadas, las catalogan a todas como sumisas y nosotras tenemos que trabajar en cuanto a la igualdad en la pareja, recordemos que los cheques de ayuda se dan a las mujeres, entonces yo tengo que trabajar por un lado con las jóvenes refugiadas, pero también con las psicólogas españolas, es un trabajo de desestereotipación... mi lucha es ser una mediadora social".

Rania también afirma que desde las protestas del 2011 el escenario político en Túnez ha sido de (re)construcción social: “... nuestra lucha ha sido ir un paso adelante y un paso atrás, un ejemplo de ello es la ley de herencia igualitaria, que nos ha dejado con mucha frustración... los islamistas han usado a las mujeres como un escaparate y siempre argumentan que luchan por la igualdad de género, pero son estrategias maquilladas para que $A l$ Nahda sea reconocido internacionalmente y se le catalogue como un partido islamista moderno, como lo que ha sucedido con la candidata islamista Suad Abderrahim, quien ha sido elegida como la primera mujer alcaldesa de la ciudad de Túnez. Es una estrategia muy hipócrita y es una vitrina y al mismo tiempo luchan en contra de las mujeres demócratas. Créeme, hemos tenido negociaciones con las mujeres islamistas para discutir la situación de las tunecinas y nos han dicho '... estamos de acuerdo con todo lo que ustedes piden, menos con la igualdad en la ley de herencia, todo menos eso', y si tú consideras que el hombre debe tener el doble, las mujeres demócratas no podemos hablar... ¿qué te digo?, estamos en una práctica continua en búsqueda de un feminismo que una o bien... tal vez... no necesitemos un feminismo unificado, global, sino que está bien tener varias líneas, es mucho más constructivo... aunque los hombres islamistas en realidad lo que buscan es cumplir con intereses políticos. Te doy otro ejemplo, en España, los inmigrantes tunecinos musulmanes, que tienen muchos años aquí, viven un problema de identidad, viven en muchas ocasiones marginados y se vuelcan en la religión y ahora que han tenido la ocasión de votar en las elecciones en Túnez, votan por Al Nahda, cuando ellos no viven en Túnez... gozan de todas las libertades (la democracia, la libertad) en España pero votan por los islamistas en Túnez, porque sienten que se fortalece su identidad. Pero es una estrategia contra feminista; además, esto provoca que los españoles y europeos nos vean como infantes eternos y se justifica el discurso salvacionista y en nuestra lucha estamos tratando de dejar ese sentimiento paternalista europeo".

En el tema de la construcción o reconstrucción política, Rania menciona la importancia de generar una reexistencia como mujeres tunecinas: "Por ejemplo, yo no soy una mujer árabe, yo me puedo catalogar como una mujer tunecina, magrebí y africana; pero yo soy bereber arabizada y no soy una vándala; ni siquiera los países del Golfo nos reconocen como árabes. Tenemos el deber de buscar nuestros orígenes, nuestras tradiciones y darnos un nuevo nombre. No todo gira en torno al Islam. Por ejemplo, yo no te pregunto, en primera instancia, si eres cristiana o judía... por qué nos deben de catalogar por la religión; a mí siempre me preguntan si soy musulmana... por qué se permiten vincularnos primero con la religión... para nosotras la religión era más bien una cuestión cultural y ahora con la llegada de los 


\section{Entrevista a Rania Benzina. La dicotomía del proceso emancipatorio político y social de las tunecinas}

islamistas se ha generado una identidad impuesta, una identidad que no tuvimos oportunidad de elegir. La religión no tiene por qué limitar mi identidad, hoy creo y mañana no. Tenemos que decidir qué entendemos al definirnos como tunecinas y ese es el trabajo al que nos enfrentamos en este momento (Benzina, 2020).

Rania finaliza haciendo un análisis de los objetivos de la lucha feminista en Túnez y sostiene: "Me gustaría ver una presidenta en Túnez, pero una mujer que provenga de la lucha y que para entonces hayamos cambiado las estructuras y relaciones de poder; porque el poder corrompe, no sólo se trata de que llegue una mujer sino de que el sistema cambie, de nada sirve que una feminista alcance el poder si las estructuras siguen siendo las mismas. Esto no es fácil, por ello debemos darle continuidad a la lucha, ocupar los espacios públicos, inscribirnos en el ámbito educativo y reescribir la historia de las mujeres, tenemos que seguir la lucha en contra de la violencia y del acoso. Además, el contexto de la pandemia nos ha violentado aún más, se han incrementado la delincuencia, la desigualdad social y la violencia doméstica. También ha aumentado la violencia contra las mujeres en las calles, especialmente por los toques de queda. Ese es nuestro panorama y por eso no debemos bajar la guardia. Ustedes tienen otras luchas, pero considero que hay que mantener la tela de araña o el hilo conductor, porque en África y en América Latina tenemos muchas cosas por hacer como feministas.

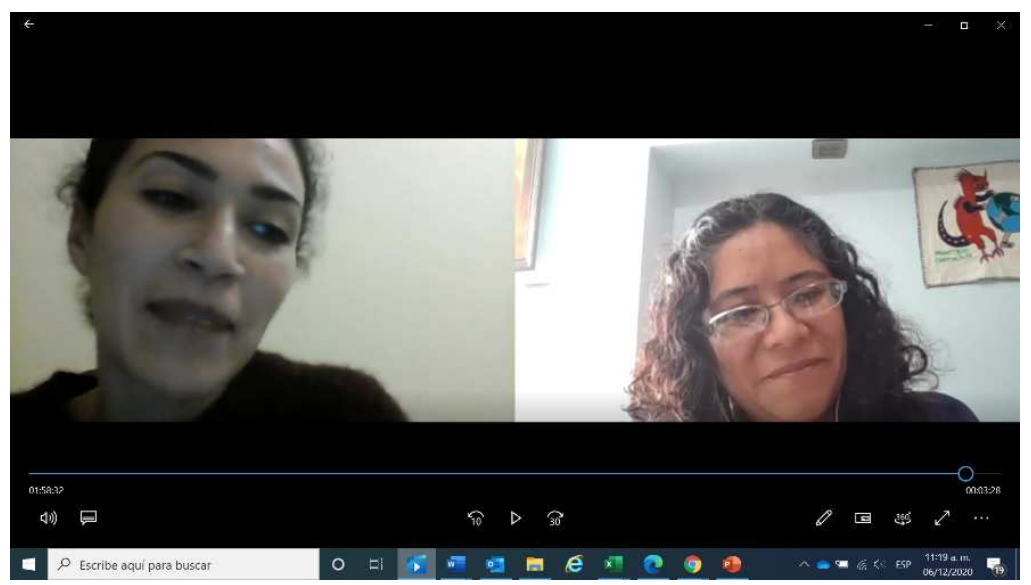

Entrevista con Rania Benzina (izquierda), vía virtual, el día 27 de noviembre de 2020

\section{Reflexiones finales}

Inés Chaalala y Thouraya Bekri Hammami hacen un análisis señalando que las tunecinas han ido ganando muchos espacios de lucha, sin embargo las disparidades sociales, la explotación femenina y la violencia siguen existiendo, y es por ello que las tunecinas siguen luchando.

Las tunecinas, quienes representan el 50,5 \% de la población, constituyen el 63,6 \% de lxs premiadxs con el bachillerato, $68 \%$ de lxs que obtienen un diploma superior, $49 \%$ de lxs ejecutivxs superiores y técnicos, $39 \%$ en la función pública. Son 


\section{Indira Sánchez Bernal}

ampliamente representadas en algunos oficios como la magistratura (32\%), la abogacía (31\%), la medicina (42\%), la farmacia (27\%), la enseñanza universitaria (40\%). Pero son sólo el $6 \%$ en ocupar puestos de decisiones y se benefician sólo del $17 \%$ de los nuevos empleos creados. La tasa de desempleo de las mujeres es del $21,9 \%$ comparado con el 12,8 \% de los hombres y una media nacional de 15,7 \%. Esta cifra se agrava más para las mujeres con diploma de la enseñanza superior, el $43 \%$ se quedan sin empleo (contra 23\% para los hombres y una media nacional de $33,5 \%)$. A esto se añaden importantes disparidades regionales, por ejemplo, tasas de actividad femenina en las regiones semiáridas del país (Kasserine, Kebili y Gafsa) inferiores al $25 \%$, cuando es superior al $40 \%$ en la mayoría de las regiones litorales; o tasas de escolarización en el nivel primario que varían de 80,7 \% en entorno urbano hasta 59,3 \% en entorno rural (Chaalala \& Hammami, 2020).

A través de la conversación sostenida con Rania Benzina, hemos podido visualizar que hay una dicotomía en la lucha feminista entre quienes defienden la lucha contra la estructura patriarcal desde el Islam, a través del Corán y la sharía (ley islámica) y las que defienden el derecho de separarse de la identidad religiosa y de redefinir qué significa ser una mujer tunecina en otros términos.

Desde el año 2011 las tunecinas han abierto espacios para la participación política no sólo para mujeres árabes, educadas y de clase media, ya que se han integrado al debate mujeres bereberes pertenecientes a diferentes clases sociales con lo que la agencia ciudadana de las mujeres se ha reforzado. Hay que señalar que uno de los grandes logros en Túnez ha sido traspasar el sectarismo identificado con lo étnico (lo mismo ha sucedido en países como Líbano). Las demandas se encuentran enfocadas más en la resolución de problemas sociales que necesariamente en las divisiones heredadas de la colonización.

Gran parte de la participación política se ha dado desde los canales laicos, por supuesto, como lo pudimos observar en la entrevista y a lo largo del desarrollo del presente texto, pero también ha ocurrido desde canales islamistas. Las mujeres han tenido la capacidad de decidir si deben usar o no un velo, o bien mantener o no su religión como parte de una identidad cultural o como una herramienta política que contrarresta las estructuras del poder político.

Deseo comentar en este espacio que durante la conversación con Rania hubo momentos en los que brotaron muchas contradicciones. Por un lado, Rania acusa a las islamistas tunecinas de contribuir al poder patriarcal, pero al mismo tiempo en España defiende la identidad musulmana como una identidad no victimizada, y me parece que esto se debe a la condición liminar y al racismo epistémico que afronta Rania en su cotidianidad. Es una tunecina musulmana y a la vez laica que vive en un espacio eurocentrado y que se acercó al feminismo a través de textos escritos en español, lo cual hace pensar que defiende la lucha de las mujeres en Túnez alejándose de la religión. Desde España, defiende la idea de que las musulmanas no se conviertan en víctimas infantilizadas, sujetas de rescate por la superioridad epistémica europea. 


\section{Entrevista a Rania Benzina. La dicotomía del proceso emancipatorio político y social de las tunecinas}

El racismo epistémico en la forma de islamofobia epistémica, es una lógica fundamental y constitutiva del mundo moderno/colonial y de sus formas legítimas de producción del conocimiento. Desde el siglo XVI, los humanistas y eruditos europeos han sostenido que el conocimiento islámico es inferior al de occidente (Grosfoguel, 2012, 51).

Dicho racismo epistémico fue expresado a través del síndrome del hombre blanco salvador, sustentado en la defensa de la democracia, la liberación de las mujeres oprimidas por el yugo de los hombres musulmanes, la sustentación de los derechos humanos y la motivación del establecimiento de regímenes seculares. El discurso salvacionista fue utilizado por los gobiernos estadounidenses y europeos, precisamente por aquellos que lograron inmiscuirse en los territorios afganos, iraquíes, libios, en los años 2001, 2003 y 2011, respectivamente (me refiero a Estados Unidos, España, Inglaterra, Australia, entre otros).

Las mujeres musulmanas fueron presa del discurso salvacionista euroestadounidense, ya que se les presentó como víctimas pasivas oprimidas por los hombres musulmanes y por la religión islámica. Opresión representada por el uso del velo y de cualquier vestimenta que cubriera la cabeza y el cuerpo.

Elia Shohat y Robert Stam, en su obra Tropos del Imperio, mencionan que las metáforas, los tropos y los motivos alegóricos han desempeñado un papel primordial a la hora de configurar la superioridad europea; de esta forma, aquellas personas que fueron colonizadas son presentadas como cuerpo y no como mente. Por ende, a las mujeres musulmanas independientemente del contexto histórico, se les ha criticado por ir demasiado vestidas y por poseer cuerpos demasiado tapados (Shohat \& Stam, 1994). Por extensión, la vestimenta se vincula a fenómenos como la poligamia, la lapidación, la ablación; procesos todos, considerados como una violación flagrante a los derechos humanos e intrínsecos a la práctica del Islam. Chandra Mohanty, especifica que "la noción monolítica del patriarcado nos guía hacia una noción reduccionista y homogénea de lo que es el tercer mundo" (Mohanty, 2008:5).

Muchos son los que se esconden tras los valores del laicismo y la igualdad entre hombres y mujeres para expresar su rotundo rechazo al uso del velo en lugares públicos: el hiyab es en gran medida identificado por la mayoría del pueblo francés como la expresión de una amenaza islámica y el símbolo de un nuevo fundamentalismo del mismo tipo que pone en peligro los valores fundamentales laicos y republicanos (Geisser, 2012, 67).

Otro debate fuerte que puede extraerse de la entrevista, es el que existe entre la idea de la complementariedad y la igualdad, pero es una discusión que ha sido apropiada por las tunecinas, sean islamistas o laicas, a veces dando pasos atrás y otros hacia adelante como señalaba Rania. Las luchas han integrado, además, la interrogante sobre la viabilidad de dar continuación a un modelo económico que demostró ser generador de desigualdades sociales y económicas. Actualmente, las tunecinas trabajan por un modelo más colectivo e inclusivo, dignificando el trabajo de cuidado realizado por las mujeres y defendiendo el derecho a la posesión de la tierra. 


\section{Indira Sánchez Bernal}

Sin duda, las feministas en Túnez han dado un nuevo significado a la acción sociopolítica en los movimientos sociales del país y de la región abriendo canales de negociación y de discusión. Las mujeres tunecinas se encuentran en la misma encrucijada de las luchas y movimientos sociales a nivel global, esto es, encontrar los canales adecuados para existir y reexistir sin caer en el peligro de la inacción política o de la faccionalización, al grado de encontrarse con nuevas dinámicas de control, manipulación, dominio o arribo de grupos ultraconservadores, que vuelvan a invisibilizar la lucha que han realizado las tunecinas durante tantos años.

La experiencia de lucha de las mujeres tunecinas se devela tensa y muy rica en el proceso de generar una identidad como tunecinas, magrebíes y africanas.

\section{Bibliografía}

Bueno, J. (2012). Las mujeres en las revueltas árabes: una voz de alarma frente a una religiosidad imperante". Pasajes, (39), Universitat de Valencia.

BBC, Mundo, “Cómo Túnez se convirtió en el país más feminista del mundo árabe?” del 17 de enero de 2017 en https://www.bbc.com/mundo/noticias-internacional38646934

Chaabani, F. (2018). La participación de la mujer tunecina en la construcción de la paz: participación relevante en la transición democrática. Revista de estudios socioeducativos, (6). Disponible en: https://revistas.uca.es/index.php/ReSed/article/view/S.2.7N6/5396

Chaalala, I. \& Hammami BekriI, T. (2020). Túnez: el rol de las mujeres en la construcción democrática. iFeminismos! Eslabones fuertes del cambio social. Disponible en: https://www.ritimo.org/Tunez-el-rol-de-las-mujeres-en-laconstruccion-democratica

De Larramendi Martínez, M. (2000). Argelia, Túnez, Mauritania y Libia durante los años noventa, entre el pluralismo autoritario y el ocaso de las masas. Cuadernos de estrategia, (106).

Mahfoud - Draoui, Dorra (2018). Les femmes tunisiennes dans le travail et le mouvement syndical. Túnez: Friedrich Ebert Stiftung.

Melara Navío, A. G. (Traductor) (2004). El Noble Corán y su traducción -comentario en lengua española. Medina al Munawwara, Arabia Saudita: Ministerio de Asuntos Islámicos, 2004.

Farhat, Z. (2005). Estatuto de la mujer tunecina: conciencia de ciudadana y responsabilidad de Estado. Afkar/Ideas. Disponible en: 


\section{Entrevista a Rania Benzina. La dicotomía del proceso emancipatorio político y social de las tunecinas}

https://www.iemed.org/observatori/areesdanalisi/arxiusadjunts/afkar/afkar ideas 7/Estatuto de la mujer tunecina

Geisser, V. (2012). Islamofobia: ¿Una especificidad francesa en Europa? En G. Martín Muñoz y R. Grofoguel (eds.) La islamofobia a debate: la genealogía del miedo al islam y la construcción de los discursos antiislámicos. Madrid: Casa Árabe.

Grosfoguel, R. (2012). Islamofobia epistémica y ciencias sociales coloniales. En G. Martín Muñoz y R. Grofoguel (eds.) La islamofobia a debate: la genealogía del miedo al islam y la construcción de los discursos antiislámicos. Madrid: Casa Árabe.

Haddad, T. (2018). Notre Femme dans le charia et la societé. Túnez: Nirvana.

Jorge Lema, G. (2018). La revolución tunecina, una perspectiva social. Instituto Español de Estudios Estratégicos. Disponible en: .http://www.ieee.es/Galerias/fichero/docs opinion/2018/DIEEE0022018 Revolucion Tunez GloriaJorgeLema.pdf

Lacomba, J. (2000). Emergencia del islamismo en el Magreb: las raíces sociopolíticas de los movimientos islamistas, Madrid, Catarata, $224 \mathrm{pp}$,

Mahmood, S. (2001). Feminist Theory, Embodiment, and the Docile Agent: Some Reflections on the Egyptian Islamic Revival. Cultural Antrophology, 16 (2).

Mesa Delmonte, L. (2012). El pueblo quiere que caiga el régimen: protestas sociales y conflictos en África del norte y en Medio Oriente. México: El Colegio de México, Centro de Estudios de Asia y África.

Mohanty Talpade, C. (2008). Bajo los ojos de occidente. Academia feminista y discurso colonial. En L. Suárez Navaz y A. Hernández (edit.) Descolonizando el Feminismo: Teorías y Prácticas desde los Márgenes. Madrid: Editorial Cátedra.

Montoro, R. (1992). La mujer tunecina en busca de un papel social: la obra literaria de Arūsiyya al-Nālūtī, Miscelánea de Estudios Árabes y Hebraicos. Sección ÁrabeIslam, (41). Disponible en: http://cort.as/-8oYX

Ortega Fuentes, A. (2015). El movimiento sindical en Túnez y en Egipto: colaboración, disidencia y renovación (Tesis Doctoral inédita). Universidad Autónoma de Madrid, Facultad de Filosofía y Letras, Departamento de Estudios Árabes e Islámicos y Estudios Orientales. Disponible en: https://repositorio.uam.es/bitstream/handle/10486/669590/ortega fuentes alej andra.pdf?sequence $=1$

Proyecto de la Constitución tunecina de 2014 en español en https://www.constituteproject.org/constitution/Tunisia 2014.pdf?lang=es 


\section{Indira Sánchez Bernal}

Ramírez, A. (2012). Feminismos Musulmanes: historias, debates y límites. En Hernández Corrochano et al. Teoría feminista y antropología: claves analíticas. Madrid: Editorial Centro de Estudios Ramón Areces. Disponible en:

https://gruposhumanidades14.files.wordpress.com/2014/10/c3a1ngelesramc3adrez-feminismos-musulmanes historia-debates-y-lc3admites.pdf

Ruiz-Almodóvar, C. (1995). El Código Tunecino de Estatuto Personal, Miscelánea de Estudios Árabes y Hebraicos, Sección Árabe-Islam, (44).

Salem, S. (2014). Feminismo islámico, interseccionalidad y decolonialidad. Tabula Rasa, (21), Universidad Colegio Mayor de Condinamarca, Colombia.

Shohat, E. \& Stam, R. (1994). Multiculturalismo, cine y medios de comunicación: crítica al pensamiento eurocéntrico. Buenos Aires: Paidós.

Todd, E. (2003). Después del Imperio, ensayo sobre la descomposición del sistema norteamericano. Madrid: FOCA.

Western, W.; Galindo, A. \& Sánchez, I, (2014). Voces, tramas y trayectorias: las protestas populares en Medio Oriente y Norte de África. Monterrey: Universidad Autónoma de Nuevo León y Universidad de Monterrey.

Western, W. \& Galindo, A. (2018). Voces, tramas y trayectorias: transiciones críticas en el Medio Oriente y Norte de África. Monterrey: Universidad Autónoma de Nuevo León y Universidad de Monterrey.

Yacoubi, I. (2016). Sovereignity From Below: State Feminism and Politics of Women against Women in Tunisia. The Arab Studies Journal, 24 (1).

Youssef, 0. (2007). Le Coran au risque de la Psychoanalyse. Francia: Alba Michel.

\section{Entrevista}

Entrevista virtual a Rania Benzina, el día 27 de noviembre de 2020.

Recibido: 30/11/2020

Evaluado: $30 / 01 / 2021$

Versión Final: 26/02/2021 